NBSIR 86-3373

\title{
Impact of Refrigerant Property Uncertainties on Prediction of Vapor Compression Cycle Performance
}

Piotr A. Domanski

David A. Didion

U.S. DEPARTMENT OF COMMERCE

National Bureau of Standards

Center for Building Technology

Building Equipment Division

Gaithersburg, MD 20899

December 1986

Issued February 1987

Sponsored by:

Office of Buildings and Community Systems

U.S. Department of Energy through Oak Ridge National Laboratory under contract DE-AC05-840R21400 with Martin Marietta Energy Systems, Inc. 



\section{IMPACT OF REFRIGERANT PROPERTY}

\section{UNCERTAINTIES ON PREDICTION OF}

\section{VAPOR COMPRESSION CYCLE}

\section{PERFORMANCE}

Piotr A. Domanski

David A. Didion

U.S. DEPARTMENT OF COMMERCE

National Bureau of Standards

Center for Building Technology

Building Equipment Division

Gaithersburg, MD 20899

December 1986

Issued February 1987

Sponsored by:

Office of Buildings and Community Systems

U.S. Department of Energy through

Oak Ridge National Laboratory under

contract DE-AC05-84OR21400 with

Martin Marietta Energy Systems, Inc.

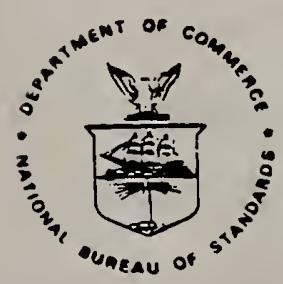

U.S. DEPARTMENT OF COMMERCE, Malcolm Baldrige, Secretary NATIONAL BUREAU OF STANDARDS. Ernest Ambler, Director 



\section{Executive Summary}

Considerable reliance is placed on compter simulation models for evaluation of potential performance enhancement concepts. As the potential of new working fluids is evaluated, the impact of uncertain refrigerant properties needs to be better understood to properly interpret the se computer simulation results. This paper presents a study of sensitivity of performance prediction to refrigerant properties for a residential, split heat pup operating in the cool ing mode. The NBS steady-state heat pump mode1, HPSIM, was used in this study. The individual influence of the following parametric uncertainties was exam ined:

1 iquid thermal conductivity vapor thermal conductivity

1 iquid $v$ iscosity

$\nabla$ apor $\nabla$ iscosity

1 iquid specific $\nabla 01$ ume

vapor specific vol une

1 iquid heat capacity

vapor heat capacity at constant $\nabla 01$ ume and heat capacity

at constant pressure

evaporatior heat transfer coefficient

condensation heat transfer coefficient

evaporation pressure drop

condensation pressure drop

The influence of a given parameter on the performance prediction was found by execoting the program, HPSIM, with the al tered parameter value. Several runs were executed for each tested parameter to cover the uncertainty range within which the value of this parameter would be expected to be known Comparison of the heat pump capacity and power input with results of a run using an unchanged $\nabla$ al ue of the parameters described the sensitivity of the cycle to each parameter. The effects on evaporator and condenser pressures and refrigerant mass flow rate are al so given in the report. 
Discrepancy between heat pump laboratory test results and computer model predictions may stem from uncertainties in refrigerant property predictions and inadequa te hardware modeling a 1 gorithms. The impact of inaccurate property values can be evaluated using the findings of this study, the impact of simplifications in modeling al gorithms have to be determined indivioual $1 \mathrm{y}$ for each computer model.

Results of this sensitivity study are system dependent (e.g. somewhat different results would be obtained for a system with different relative sizes of heat exchangers), however, no change of the relative importance of the inestigated parameters should be observed.

Best know ledge of all refrigerant parameters is essential for accorate performance predictions since the impact of individual parameter uncertainties may superimpose. The study indicated those parameters, which at the present state of the art, have the greatest impact on the uncertainty of performance prediction of the heat pump operating in the cooling mode. These parameters are: 1 iquid transport properties, evaporative heat transfer coefficient and vapor density.

The effect of an individual parameter variation within the tested uncertainty 1 inits was found to be as high as $7.5 \%$ for capacity (for 1 iquid therma 1 condactivity) and 65 for power (for vapor specific volume). Calculations, Which combined effects of individual parameter variations for a system charged with refrigerant 22 , showed that uncertainty of capacity and cop predictions may be as high as $12.9 \%$ and $10.9 \%$, respectively, if the involved refrigerant parameters are known with an error equal to the maximum deviation of the 
considered property correlations, and if the errors superimpose. Since properties of refrigerant 22 are among the best known, the uncertainty of capacity and COP predictions for other refrigerants and mistures may be expected to be greater. 


\section{AB STRACT}

This paper presents a sensitivity study of a vapor campression cycle in the form of a heat pmp operating in the cooling mode. The stady was performed with the aid of a detailed heat punp compater mode1; simalation runs were made for different parametric values and the capacity and power input were compared with results of a run using an unchanged $v$ al ue of the parameters. The effects on evaporator and condenser pressures, and refrigerant mass flom rate are given. The independent variables (parameters) inclode themodynamic and transport properties, as wel 1 as the Iefrigerant flow heat transfer and pressure drop coefficients. When considering the state-of-theart 1 imits of the indivianal parameter nncertainties, those which had the most effect on system performance were 1 iquid transport properties, evaporative heat transfer coefficient and $\nabla$ apor density.

Key Rords: Air conditioner, heat punp, sensitivity study, thermodynamic properties, transport properties, vapor compression cycle 
EXECUT IVE SUMMARY . . . . . . . . . . . . . . . . . $\frac{\text { Page }}{i i i}$

ABSTRACT . . . . . . . . . . . . . . . . . . . . . vi

LIST OF FIGURES . . . . . . . . . . . . . . . . . . . . . . viii

1. INTRODUCT ION . . . . . . . . . . . . . . . . . . . 1

2. HEAT PUMP SIMULATION MDDEL USED . . . . . . . . . . . . . . . 3

3. RESULTS . . . . . . . . . . . . . . . . . 6

3.1 Sensitivity to Liquid Viscosity Change . . . . . . . . . . . 7

3.2 Sensitivity to Vapor Viscosity Change. . . . . . . . . . . . . 9

3.3 Sensitivity to Liquid Thermal Conductivity Change . . . . . . 9

3.4 Sensitivity to Vapor Thermal Conductivity Change . . . . . . . 11

3.5 Sensitivity to Liquid Specific Vol une Change . . . . . . . . . 12

3.6 Sensitivity to Vapor Specific Volme Change . . . . . . . . . 14

3.7 Sensitivity to Liquid Heat Capacity Change... . . . . . . . 16

3.8 Sensitivity to Change of Vapor Heat Capacity

at Constant Pressure and Vapor Heat Capacity

of Constant Volume . . . . . . . . . . . . . . . 17

3.9 Sensitivity to Change of Evaporative Heat

Transfer Coefficient . . . . . . . . . . . . . 19

3.10 Sensitivity to Change of Condensation Heat

Transfer Coefficient .................. 21

3.11 Sensitivity to Change of Evaporation Pressure Drop...... . 23

3.12 Sensitivity to Change of Condensation Pressure Drop . . . . 23

3.13 Sensivitity to Change of More than One Parameter........ 23

3.14 Combined Effect of Refrigerant Properties Uncertainties

on Prediction of System Performance . . . . . . . . 25

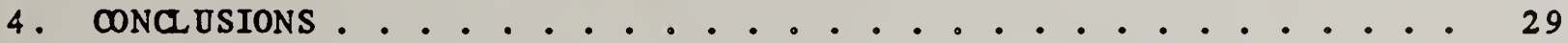

5. REFERENCES ........................... 31

APPENDIX A. EVALUATION OF THE THERMODYNAMIC PROPERTIES OF VAPOR . • . 33

APPENDIX B. EVALUATION OF THE INSIDE TUBE HEAT TRANSFER COEFFICIENT AND PRESSURE DROP OF REFRIGERANT . . . . . . . . . . . 39 
Figure 1. Schematic of a heat pump simalated by the heat pump mode 1, HPS IM . . . . . . . . . . . . . . .

Figure 2. Logic of the heat promp model used in the sensitivity study . . . . . . . . . . . . . . . . . .

Figure 3. Sensitivity of performance of a heat pump to a change in 1 iquid iscosity . . . . . . . . . . . . . .

Figure 4. Sensitivity of performance of a beat pump to a change in 1 iquid thermal condactivity............

Figure 5. Sensitivity of performance of a heat $p$ ump to a change in 1 iquid specific volme . . . . . . . . . . . . . . .

Figure 6. Sensitivity of performance of a heat pump to a change in vapor specific volme . . . . . . . . . . . . . .

Figure 7. Sensitivity of performance of a heat pump on a change in the heat capacity of 1 iquid . . . . . . . . . .

Figrre 8. Sensitivity of performance of a heat pump on a change in the evaporative heat transfer coefficient . . . . . .

Figure 9. Sensitivity of performance of a beat $p$ mp on a change in the condensation heat transfer coefficient . . . . .

Figure 10. Sensitivity of performance of a beat pump on a change in the evaporative pressure drop.......... . 24 


\section{INTRODU CTION}

Over the past decade, there has been considerable attention devoted to the performance of refrigeration systems in both simulation model studies and laboratory measurement studies. The accuracy of these studies tacitly depends on knowledge of the various refrigerant thermodynamic and transport properties as we1 1 as other flow parameters. The uncertainty with which the property val ues are known is primarily a function of the state-of-the-art accuracy of the particular property measurement technique. In the case of refrigerant mirtures, there exists very little measured data, and it is therefore necessary to empl oy mixing rules along with component data. This can increase the ancertainty from 10 to $50 \%$. For example, vapor density can be evaluated quite wel1 and usualiy is known within 2 percent uncertainty [1]; on the other hand, the specific volume of a 1 iquid mirture may have an uncertainty of as much as 15 percent if density is evaluated by a mixing rule in the neighborhood of critical temperature of the 1 orer boiling component [2]. In the case of evaporative heat transfer coefficients, the actual mirture value has been shown to be as much as 400 lower than that predicted by the ideal mixture weighting factor method [3].

The different ref rigerant property and $10 \mathrm{w}$ parameters affect the system performance with varying degrees of sensitivity. It is therefore necessary to establish the system sensitivity to each property value if the most effective information is to be obtained. Of course, accurate knowledge of Iefrigerant properties does not change the way the real system operates. However, the qualitative knowledge of the impact made by properties on performance on a one by one basis is desirable because it can establish the 1 inits of uncertainty associated with simulation of refrigerant systems. 
This, in torn, will indicate the areas most in need of further research on prediction and measurement methodologies for Iefrigerants and refrigerant mirtares.

The sensitivity analysis reported here was performed by simalating the performance of a 2.5 ton split, residential, airtoair heat pupp charged with Refrigerant 22. The heat pump was simulated in the cooling mode at DOE test A conditions [4]. Simulation of the system without altering any parameter was performed first. Then, simalation rans were performed with a specific parameter changed by an assigned maltiplication factor. The change of system performance reflected system sensitivity to the altered parameter.

Al 1 simal ation rans were performed with imposed refrigerant superheat of $10^{\circ} \mathrm{F}$ at the compressor can inlet, and imposed refrigerant subcooling of $10^{\circ} \mathrm{F}$ at the expansion device inlet. These restrictions are related to the common laboratory practice of selecting optimum Iefrigerant charge and expansion device size for a given system. These restrictions al so ensure that when simulating the system with al tered parameters, the observed change in perfor mance indeed results fiom the altered parameter with optimized cycle by the same criteria, and not fram a change in operating conditions.

The range over which a selected parameter was al tered depended basically upon the ancertainty band with which this parameter is generally znown and upon a need for presenting results of this study in same uniform fashion. The uncertainty with which a given parameter is know depends on the methodology by which the parameter is determined. If parameter determination is based on laboratory measurement, the difference between values of this parameter 
reported by two reputable sources may be considered as the necertainty of this parameter. If this parameter is determined by a theoretical correlation based on fundamental knowledge of the molecule, the difference between a predicted val ue and a laboratory measurement is considered the uncertainty.

An uncertainty band usualiy increases significantly if refrigerant mirtures instead of single refrigerants are considered. This is a result of the need for some type of miring rule to de termine the desired property based on properties known for single refrigerants. Proper assessment of possible nncertainties is complicated in some cases by the 1 ack of rel iable data and by the large discrepancies between existing data sources for the majority of compounds.

\section{HEAT PUBP SIMULATION MDDEL USED}

A computer model of a heat pump, HPSIM [5], used in this study, is a 'first principles' mode1, which was dereloped with emphasis on modeling phencmena taking place in the system on a local basis. The structure of HPSIM is modnlar with simulation of each major component handled by an independent subroutine. The model consists of 41 subprograms for heat pump component simulation, and heat transfer, fluid mechanics, and fluid property calculation The program totals approximately 5000 Fortran statements. 
For ase in this sonsitivity study tho model, HPSIM, was modified in two

areas:

- convergenco tolerances were tightened throughout the program to obtain final convergence of the thermodynamic cycle within a enthal py value 0.15 Bto per pound of circalating refrigerant.

- the logic of the program was changod to allow, in addition to existing foatures, tho imposition of a preset value of subcooling at the oxpansion dorice inlet for ay given cycle.

Heat pup components considered in HPSIM are shom in Fignre 1 . A thermodynamic cycle simulatod by the model is presentod along with the logic of the model in Figare 2 .

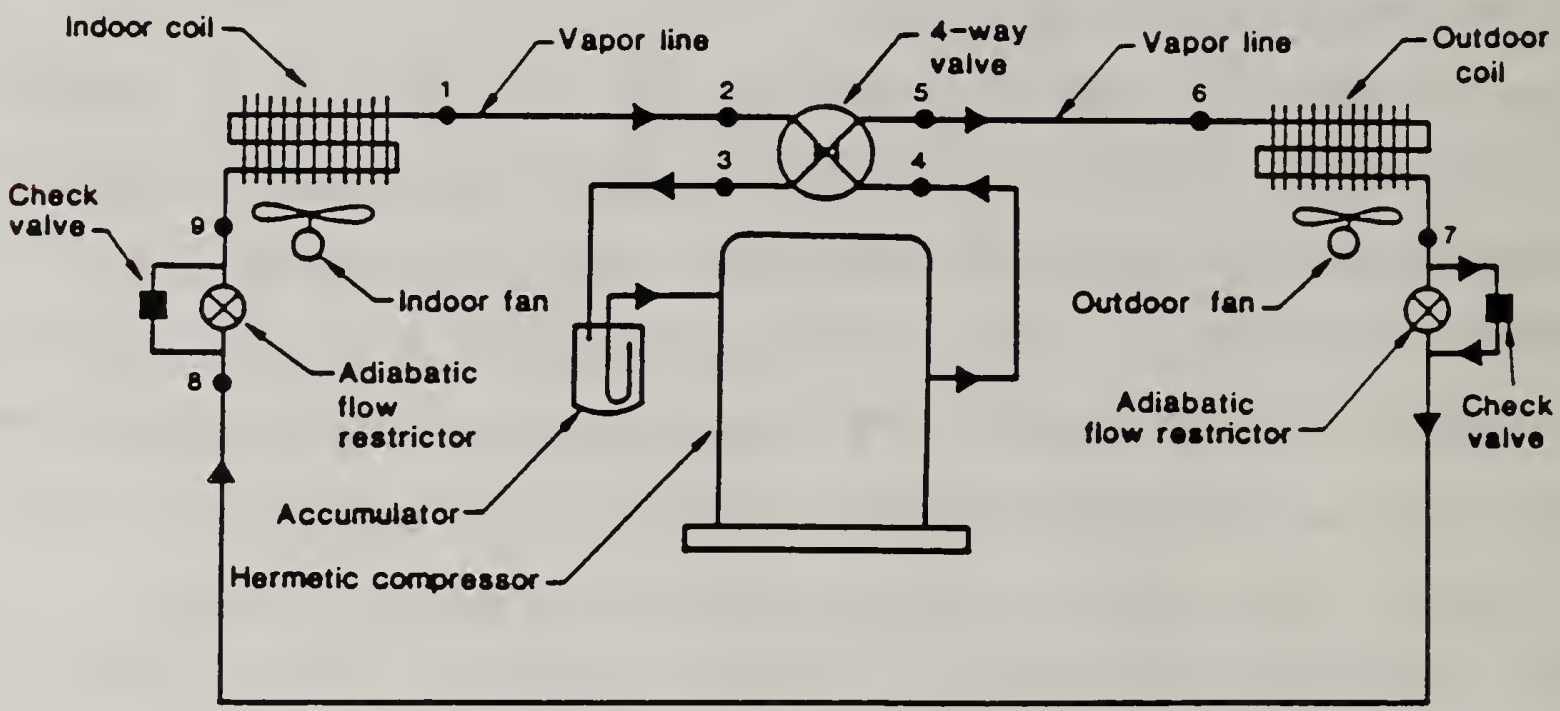

Figare 1. Scheratic of a heat pump simalated by the heat punp model, HPSIM. 


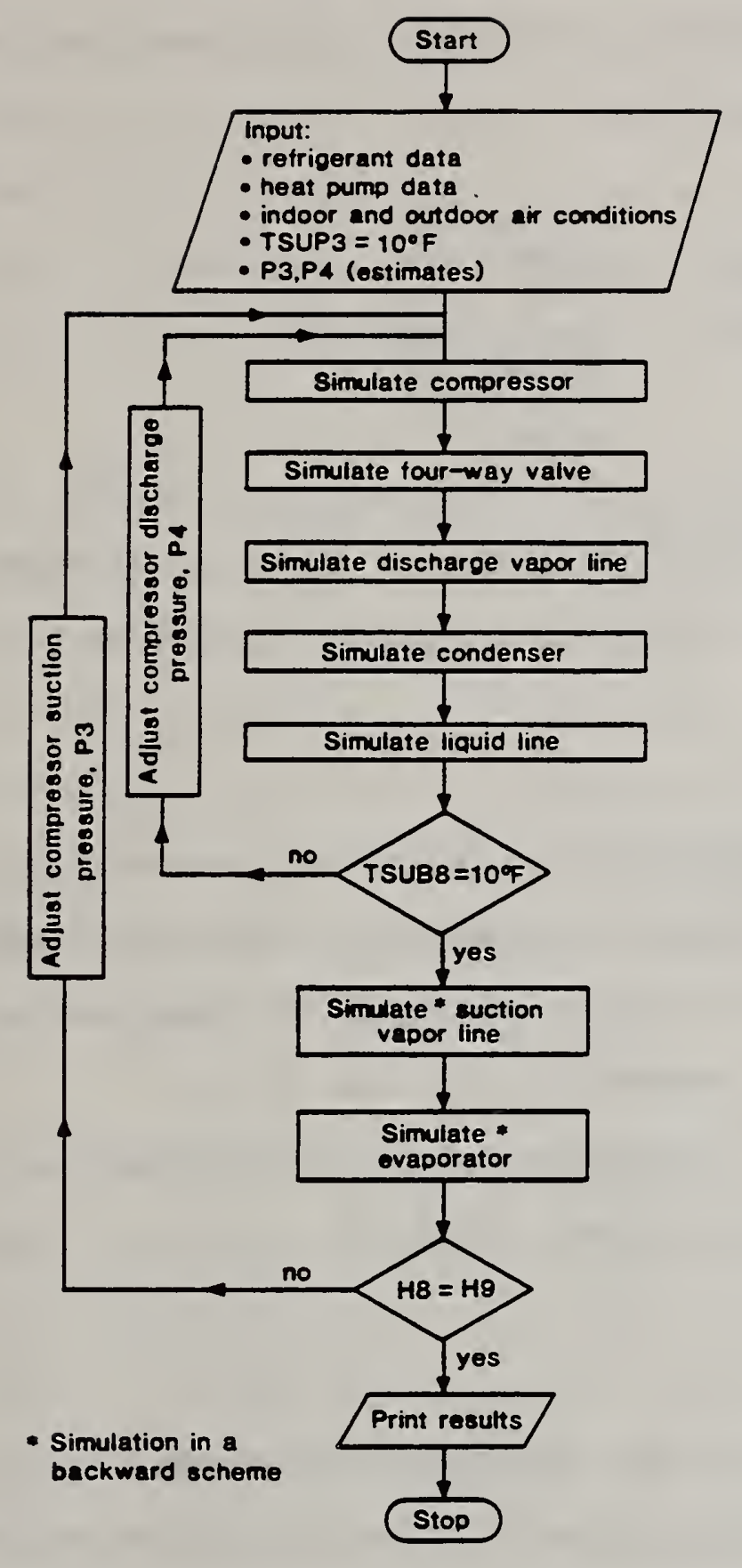

Symbols:

H8 - refrigerant enthalpy at the expansion device inlet

H9 - refrigerant enihalpy at the evaporator inlet

P3 - refrigerant pressure at the compressor can inlet

P4 - refrigerant pressure at the compressor can outlet

ISUP3 - refrigerant vapor superheat at the compressor can inlet

ISUB8 - refrigerant subcooling at the expansion device inlet

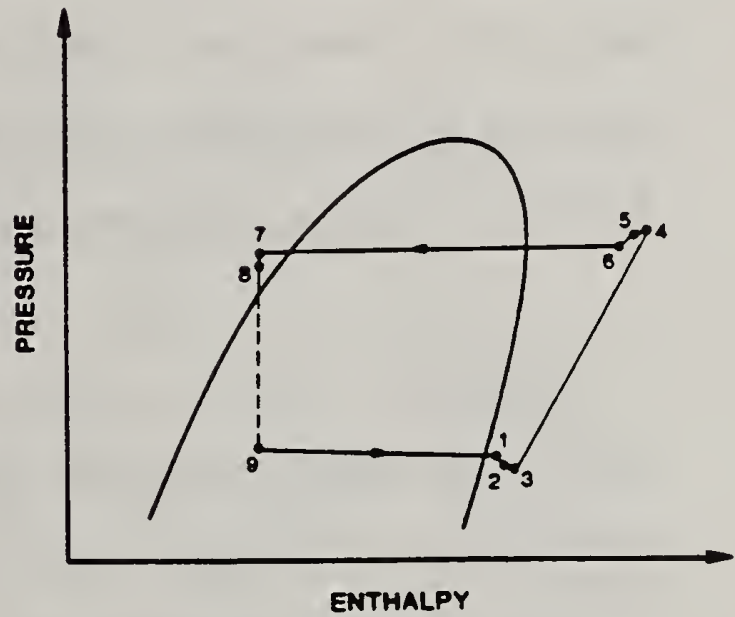

Figare 2. Logic of the heat pmp model used in the sensitivity study. 
The most important correlations for this sensitivity stody are those

associated with eval a ting the refrigerant thermodynamic state, heat transfer and pressure drop The correlations used were:

thermodynamic properties of vapor single-phase heat transfer coefficient evaporation heat transfer coefficient condensation heat transfer coefficient single-phase pressure drop evaporation pressure drop condensation pressure drop
- Dorning [6]

- Colburn [7]

- Pierre [8]

- Traviss et al. [9]

- Fanning [10]

- Pierre [11]

- Lockhart - Martinelli [12]

Equations for calculation of thermodynamic properties of vapor are presented for reference in Appendix A Other above 1 isted correlations are shown in Appendix B.

Other properties which impact on performance was studied here included:

density, heat capacity, thermal conductivity and absolute viscosity of 1 iquid, and thermal conductivity and absolute viscosity of vapor. The first four of the se were correlated as function of temperature only, 1 ast two as function of temperature and pressure. These correlations are described in Appendix A of the report on the heat pump mode1, HPSIM [5].

\section{RESOLTS}

Results presented here refer strictly to the refrigerant side of the given thermodynamic cycle, ie., capacity change refers to capacity delivered by the modeled coil not including the heat added by the indoor fan By the same principle, power input change refers to compressor power only and does not incl ude power of fans or controls. 
Results are presented in the form of figures for those parameters which, when al teredwithin the applied range changed system capacity or energy input by more than 0.5 percent. The figares sho changes of capacity (\%), energy input $(\%)$, Iefrigerant mass flow rate $(\%)$, condenser inlet pressure (psi) and evaporator outlet pressure (psi) as a function of change in a $\checkmark$ al ue of a specific property.

\subsection{Sensitivity to Liguid Viscosity Change}

Liquid viscosity data can be obtained in a number of ways. Liquid $\mathbf{p}$ iscosity obtained by direct 1 aboratory measarement or by a very 1 imited extrapolation from measured data are most reliable with a generaliy stated uncertainty of less than 5\% [1]. The best theoretical correlations provide data of an uncer tainty of $15 \%$ [13]. Methods for predicting $\nabla$ iscosity of 1 iquid mixtures are remarkably poor (uncertainties op to 23\% [13]) even when the viscosities of the pure components are accurately bown.

Simulation results are show in Figure 3. Simulation of 1 iquid viscosity at a higher $\nabla$ al ue has a detrimental effect on Iefrigerant pressure drop and the inside tube heat transfer coefficient, for both two-phase and single-phase flow. As a result suction pressure at the compressor decreases, discharge pressure increases, and mass $f$ low rate of refrigerant is decreased, which is fol 1 owed by a decrease of system capacity by 4 at $50 \%$ increase of $v$ icosity. Compressor power al so decreases but more slow iy than capacity, making the system less efficient. A 1 ower $v a 1$ ue of 1 iquid viscosity is associated with similar but opposite trends. 


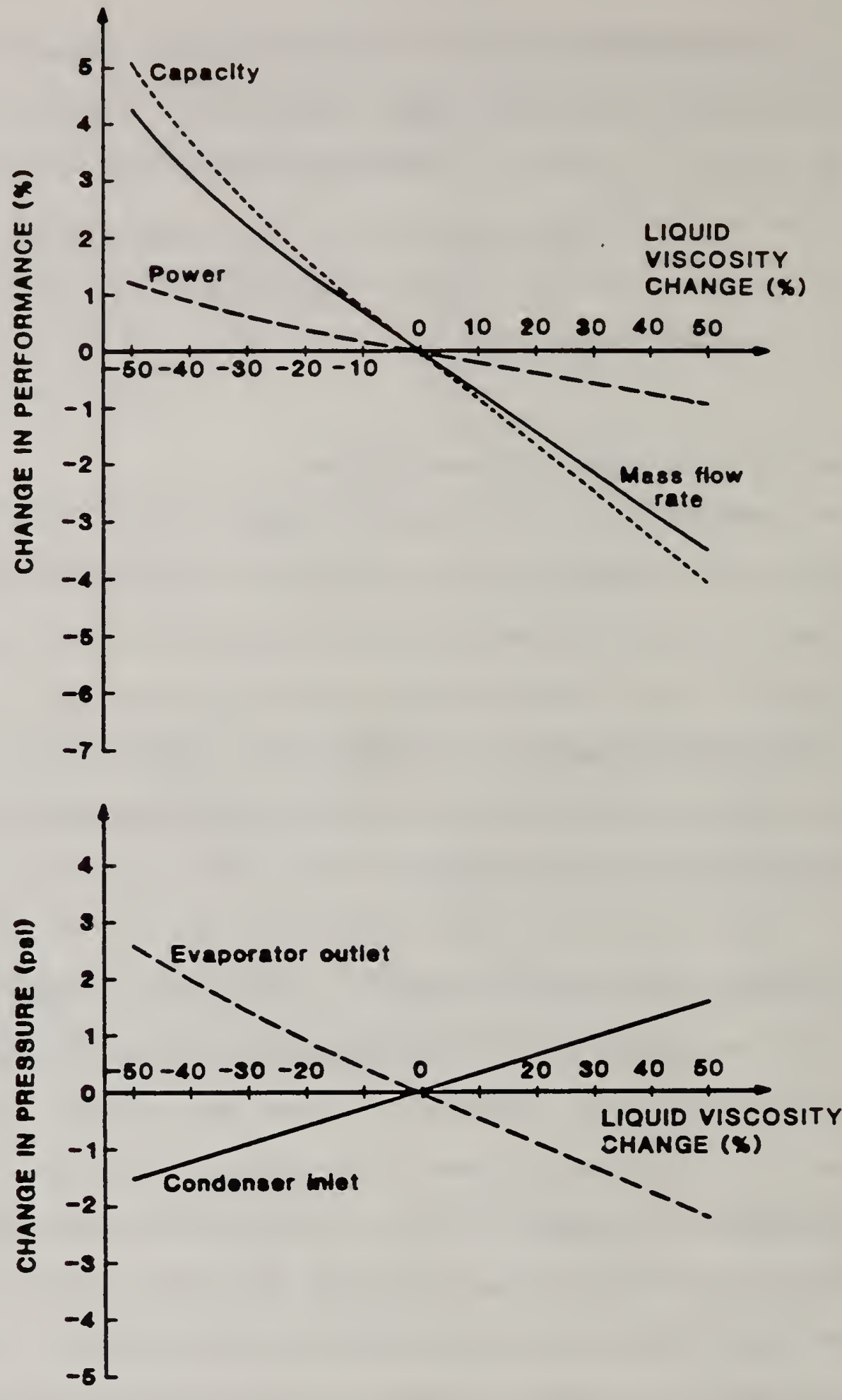

Fignre 3. Sensitivity of performance of a heat pump to a change in 1 iquid $\nabla$ iscosity. 


\subsection{Sensitivity to Vapor Viscosity Change}

Viscosity of a pure gas is usually a well know property with uncertainty less than 2\% [13]. On the other hand, viscosity of a gas mizture (if determined through the use of pure component data and miring rales rather than measurements on the mixture, of which there are few) may have an uncertainty of up to 17\% [13]. Fortunately, however, simulation rans showed a very weak sensitivity (maximum .2\%) of capacity and energy input to vapor viscosity which was varied up to $\pm 50 \%$.

\subsection{Sensitivity to Liquid Thermal Conductivity Change}

Thermal conductivity of 1 iquid, if assessed from experimental data, is known with ap to $10 \%$ uncertainty [13]. Theoretical prediction methods for this property value can have an uncertainty of up to $30 \%$. Prediction methods for mixtures al so have $30 \%$ uncertainties if 'correct' $\nabla$ iscosities of components are known.

Simulation results are presented in Figure 4. Change of 1 iquid refrigerant thermal conductivity does not affect refrigerant pressure drop in the system The observed change in 1 evel of evaporator and condenser pressures is a result of change of the inside tube heat transfer coefficient, both single-phase and two-phase, which increases with increase of 1 iquid thermal conductivity. The consequence of the improved heat transfer is that the internal saturation temperature (and thus pressure) equilibrimn levels the simulation converges to are closer to the external source and sink values. This increase of evaporator pressure and decrease of condenser pressure allows the compressor to pump more refrigerant consequently causing increased system capacity. 


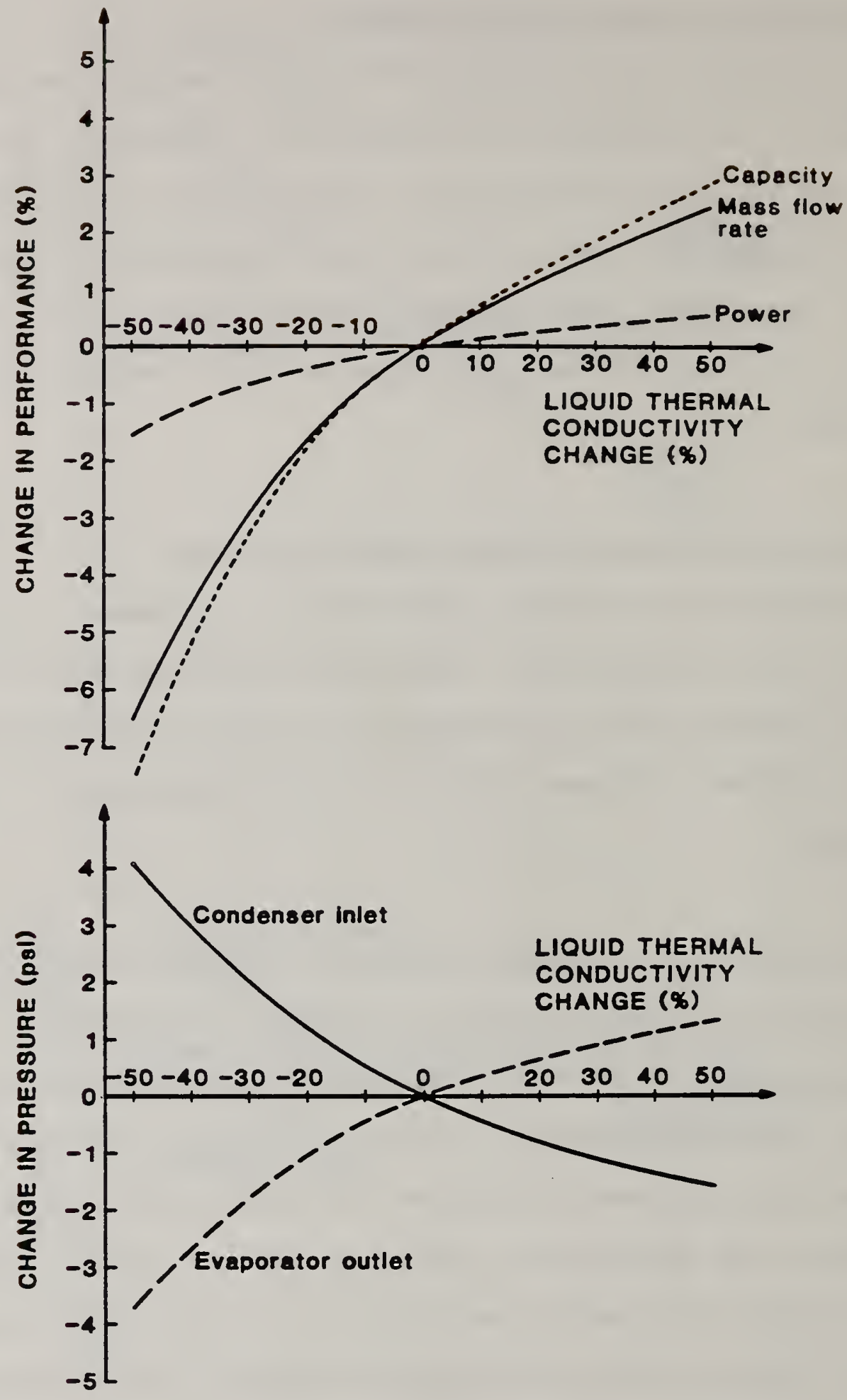

Figure 4. Sensitivity of performance of a heat pump to a change in 1 iquid thermal conductivity. 
Compressor power follows the mass flow rate pattern but not as strongly as capacity, which results in more efficient operation of the system

It is interesting to note that sensitivity of performance is not the same over the range \pm 500 at which 1 iquid conductivity was al tered. Greater impact (degradation) is exhibited for decreased conductivity than the improvement of performance for increased conductivity $(-7.6 \%$ versus $2.8 \%)$. This behavior can be explained by the fact that the 1 iquid thermal conductivity profoundy affects the inside tube heat transfer resistance. Increase of 1 iquid conductivity decreases the inside tube resistance with decreasing impact on overal 1 heat transfer resistance, making the air-side resistance an even more dominant factor, while decreasing the 1 iquid conductivity increases the inside tube resistance which becomes more significant and influential part of the overal 1 heat transfer resistance of the heat exchanger.

\subsection{Sensitivity to Vapor Thermal Conductivity Change}

Vapor thermal condectivity is usually known with an uncertainty smaller than $10 \%$ though the error can be as high as $28 \%$ [13]. Thermal conductivity of rixtures evaluated by a mixing correlation may carry an uncertainty of similar magnitude even if accurate $v$ al ues for components thermal condectivities are know.

Simulation runs performed with vapor thermal conductivity al tered from $-50 \%$ to $+50 \%$ showed very weak sensitivity of performance of the system to this prop erty. Capacity varied from $-0.5 \%$ to $0.4 \%$ respectively, while compressor power varied less than $0.1 \%$. 


\subsection{Sensitivity to Lignid Specific Volume Change}

Specific vol me of 1 iquid is asual iy know with ancertainty smaller than $1 \%$. For 1 iquid mixtures, the straight mixing rule (Amagat's 1 aw) is osually satisfactory and does not add more than $5 \%$ in uncertainty at 1 or redaced temperatures. A method based on the principle of corresponding states provides specific $\nabla 01$ we for some 1 iquid mirtares with uncertainty up to $10 \%$ [1]. None of these methods should be used at reduced temperature exceeding 0.9 for the more volatile component where prediction uncertainty may be as high as 100\% [2]; an equation of state capable of handling both the I iquid and vapor should be osed instead [14].

In the heat pump simalation program ased in this stady, Iiquid specific vol ume at saturation is calculated by an independent spline which is a fuction of temperature only. The value obtained from such a spl ine was al tered within \pm 100 in this stady. It has to be mentioned that 1 iquid specific volume has impact on the value of the latent heat and the $\mathbf{w i d t h}$ of the two-phase region (see equation (A4)) affecting the amount of heat per one poond of refrigerant that can be pumped by the cycle. Simalation results are presented in Figure 5. An increase in 1 iquid specific volue decreases latent heat, increases single-phase and to-phase pressure drop, and increases the condensation heat transfer coefficient. The evaporation beat transfer coefficient evaluated by Pierre's correlation [8], used in this study, is insensitive to 1 iquid specific volume, though other type correlations based on Lockhart-Martinelli farameter would show a decrease of the heat transfer coefficient with increased 1 iquid specific $\nabla 01$ me. The first two factors are dominant, with the latent heat being most influential; system capacity decreases inspite of 

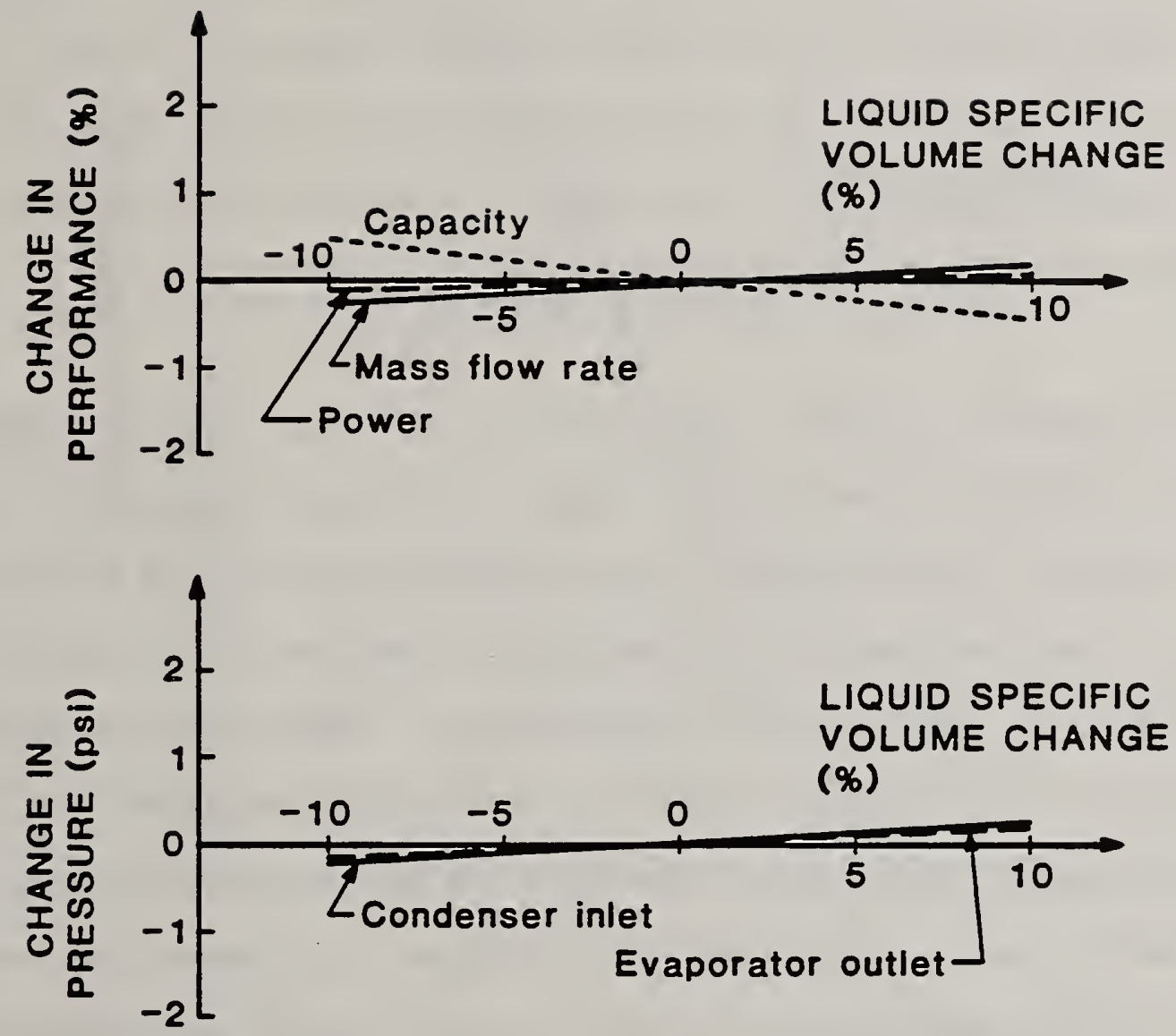

Figare 5. Sensitivity of performance of a heat pump to a change in 1 iquid specific vol me. 
increased refrigerant mass flow rate. Results for decreased 1 iquid specific vol une are symmetrical but with opposite signs than those found for increased specific vol une. However, the overal 1 performance sensitivity to this property is minimal.

\subsection{Sensitivity to Vapor Specific Volume Change}

Vapor specific volume was al tered in this study within the range \pm 100 which covers ancertainties with which this property is generaliy known. This $10 \%$ range may be exceeded in the case of mixture vapor vol mes where an unaticipated nonideal ity in the mixture may al ter the vapor pressure substantial1y; otherwise the state- of-the-art is better than $2 \%$.

Change of specific vol me of vapor affects the latent heat value similarly as specific vol me of 1 iquid but in opposite direction (see equarion (A4)), ie., the increase of vapor specific volume increases the width of the trophase region. Vapor heat capacity, enthal py and entropy are al so affected (equations (A3), (A5) and (A6), Iespectively). Other effects associated with increase of vapor specific vol me are: refrigerant mass flow rate decrease, pressure drop of single-phase vapor flow and two-phase flow increase, and condensation heat transfer coefficient increase. The changes of condensation heat transfer coefficient and pressure drop have minor and opposite affects (Figure 6). Increase of the latent heat appears to be the dominating factor, overcoming the impact of reduction of refrigerant mass flon rate (8.2\%) resulting in slightly increased capacity $(0.4 \%)$. System performance improves substantial iy at higher specific vol me since the slight capacity increase is accomapnied by decreased energy consumption. 


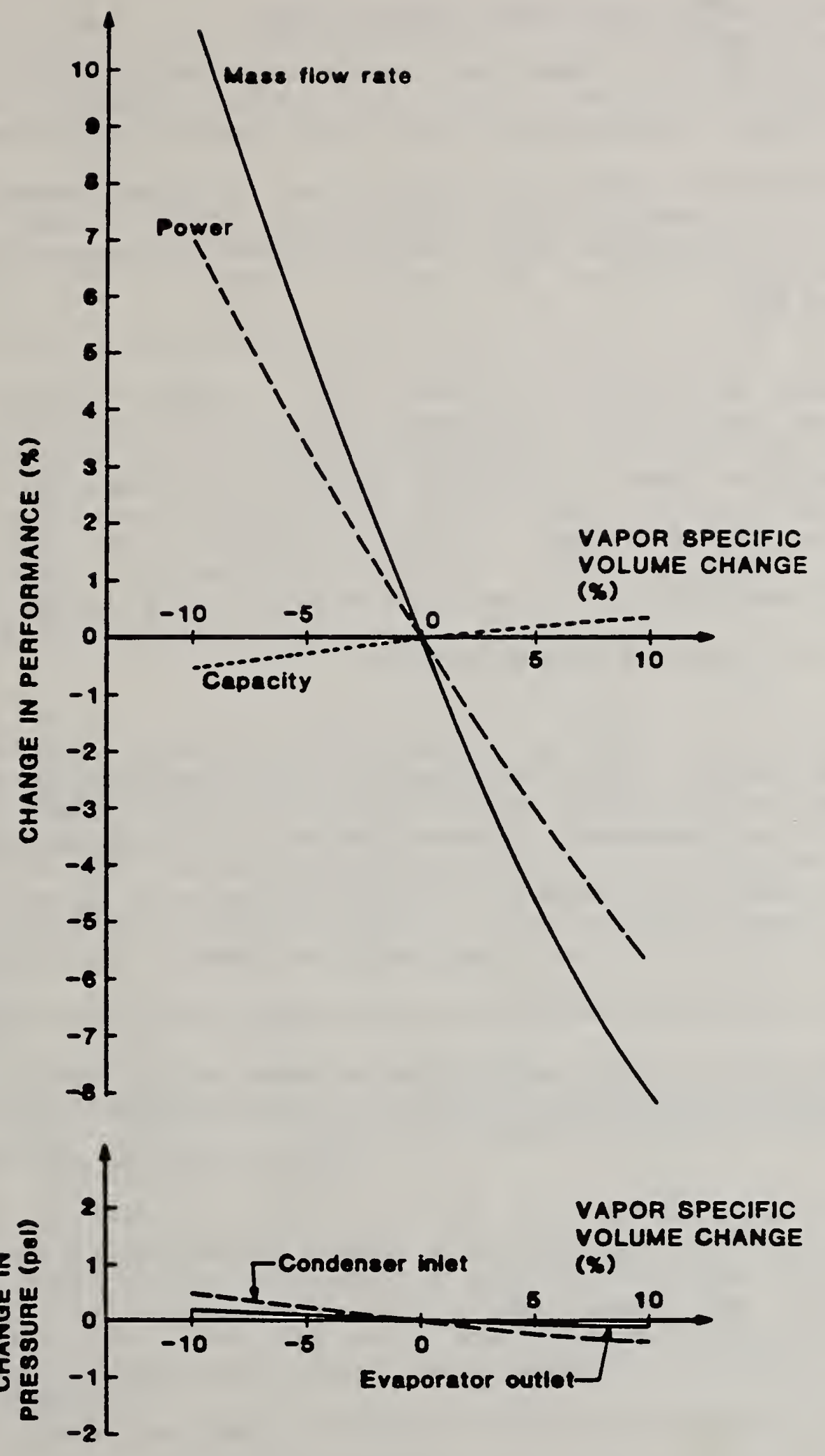

Figare 6. Sensitivity of performance of a heat pump to a change in vapor specific $\nabla 01$ mee. 


\subsection{Sensitivity to Liquid Heat Capacity Change}

Prediction methods for 1 iquid heat capacity are usualy accurate within $15 \%$ bel ow the normal boiling point, bat at higher reduced temperatures the uncertainty may be greater [1]. Specific heat of 1 iquid mixtares has an addional 5\% uncertainty due to the mixing rules for component heat capecities [13].

Liquid heat capacity as a thermodynamic property, is related to other proper ties through the slopes of saturated 1 iquid and saturated vapor 1 ines out lining the trophase region. In assessing sensitivity of system performance on I iquid specific heat it is important to realize that the outcome $\mathbf{w l} 1$ depend on the origin of the uncertainty.

Liquid beat capacity may be determined by direct measurement or by vapor phase measurement and theoretical relations outlining the tor phase region Simulation results for these two cases will differ since in the first case only ancertainty of a value of the Iiquid heat capacity will affect the accuracy of performance prediction, while in the latter case additionaliy to the $I$ iquid heat capacity, uncertainties of vapor phase measurements and theoretical relations are possibly involved.

In simalation runs, reported here, a $\nabla a 1$ ue of 1 iquid specific heat was altered exclusively. (This creates some theoretical inconsistencies since $\partial \mathrm{h} / \mathrm{T}$ for saturated 1 iquid was not changed.) As a result, the scope of sensitivity analysis is 1 imited to the effect of al tered 1 iquid heat capacity through change of the inside tube heat transfer coefficients in the heat exchangers. Consideration of uncertainty of 1 iquid heat capacity that would originate fram 
inaccurate outline of the two-phase region would require modifying of the thermodynamic properties al gorithm which was not practical for this study.

The results, shown in Figure 7, can be explained as follows:

a decrease in 1 iquid heat capacity decreases both single-phase and two-phase condensation heat transfer coefficient (pressure drop is not affected) forcing condenser pressure to increase. This increase is reinforced by increased evaporator pressure, 'pulled ap' by the condenser, and increased mass flow rate cansed by increased density of the suction vapor. Capacity decreases, in spite of greater refrigerant mass flor rate, because refrigerant enthalpy change in the evaporator decreased.

Opposite performance trends are associated with an increase of 1 iquid heat capacity with some difference in pressure change. This difference can be explained by the fact that condenser pressure decrease is 1 imited by refrigerant saturation temperature which has to be above the outdoor temperature.

\subsection{Sensitivity to Change of Vapor Heat Capacity at Constant Pressure and Vapor}

\section{Heat Capacity at Constant Volume}

Sensitivity on vapor heat capacity at constant pressure and vapor heat capacity at constant volume was tested by altering both these properties at the same time by $\pm 10 \%$. This range covers the 1 ikely uncertainties associated with the se properties. 

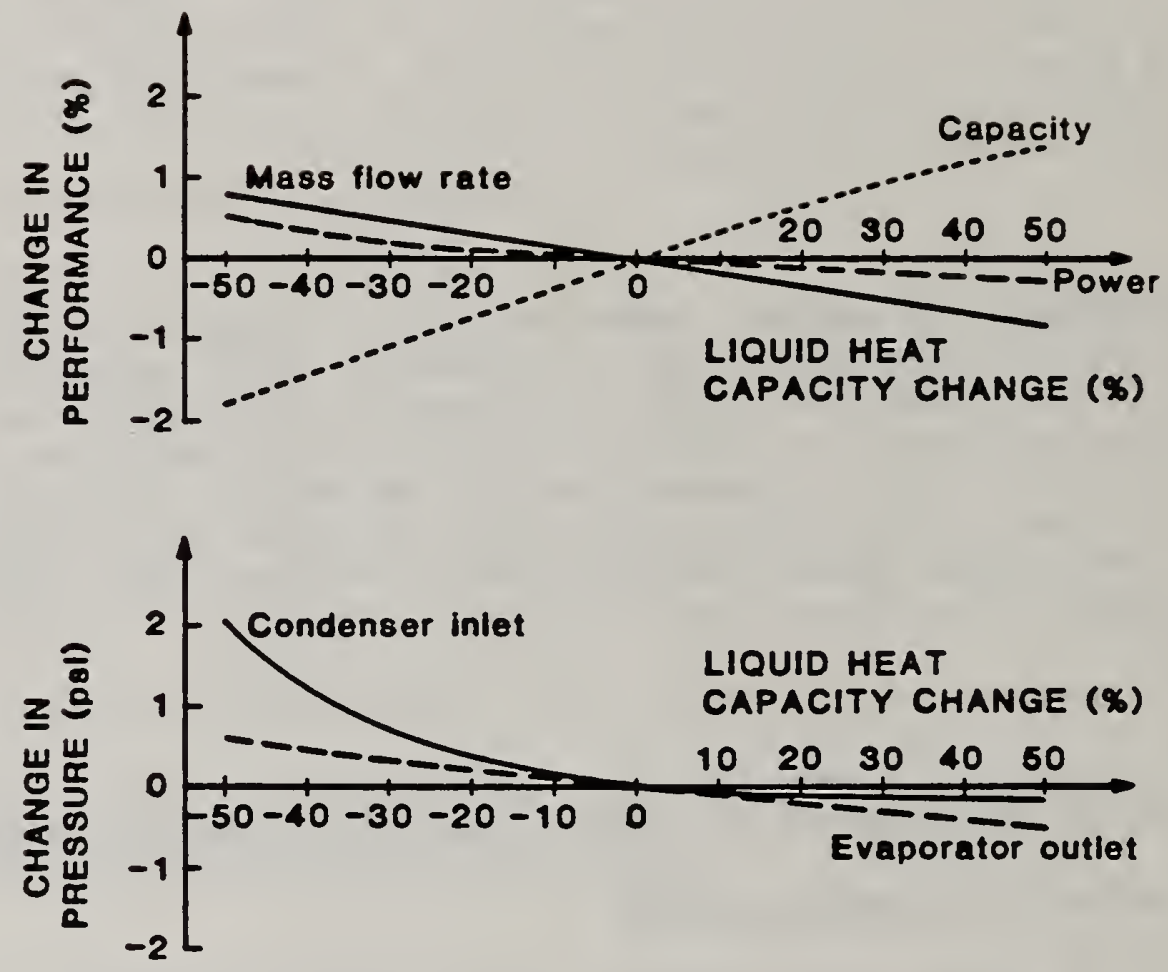

Figare 7. Sensitivity of performance of heat pump on a change in the heat capacity of 1 iquid. 
Simulation Ians showed insignificant impact on system performance resulting from the vapor heat capacities changes. Heat pump capacity and power val ues remained within $0.1 \%$ of the original level for $10 \%$ variation in heat capacities.

\subsection{Sensitivity to Change of Evaporative Beat Transfer Coefficient}

The evaporative heat transfer coefficient is one of the most difficult parameters to predict and thus has the widest variation in ancertainty. It is not uncommon that different correlations are in disagreement by as much as 50\%. Aside from eval uating the impact of the uncertainty of the evaporative heat transfer coefficient for pure components in smooth tubes, analysis of tubes with enhanced internal surfaces and Iefrigerants comprised of nor azeotropic mixtures should be al so considered. For this later case, validated miring Iules are virtual 1 y unknow however it is known that simple weighting of pure component data can result in a $40 \%$ over prediction from measured data [3].

The effect of changed evaporative heat transfer coefficient is not equally strong for its degradation and enhancement (Figure 8). The impact is stronger with degraded coefficient because in this case the inside tube heat transfer Iesistance contributes more significantly to efficiency of the heat exchange.

An increase of evaporative heat transfer coefficient allows for smaller temperature difference between the ambient air and refrigerant in the evaporator causing evaporator pressure to increase. Subsequently, the suction vapor density increases ensbling the compressor to pump more refrigerant. Since heat transfer resistance on the condenser side is not changed, the 

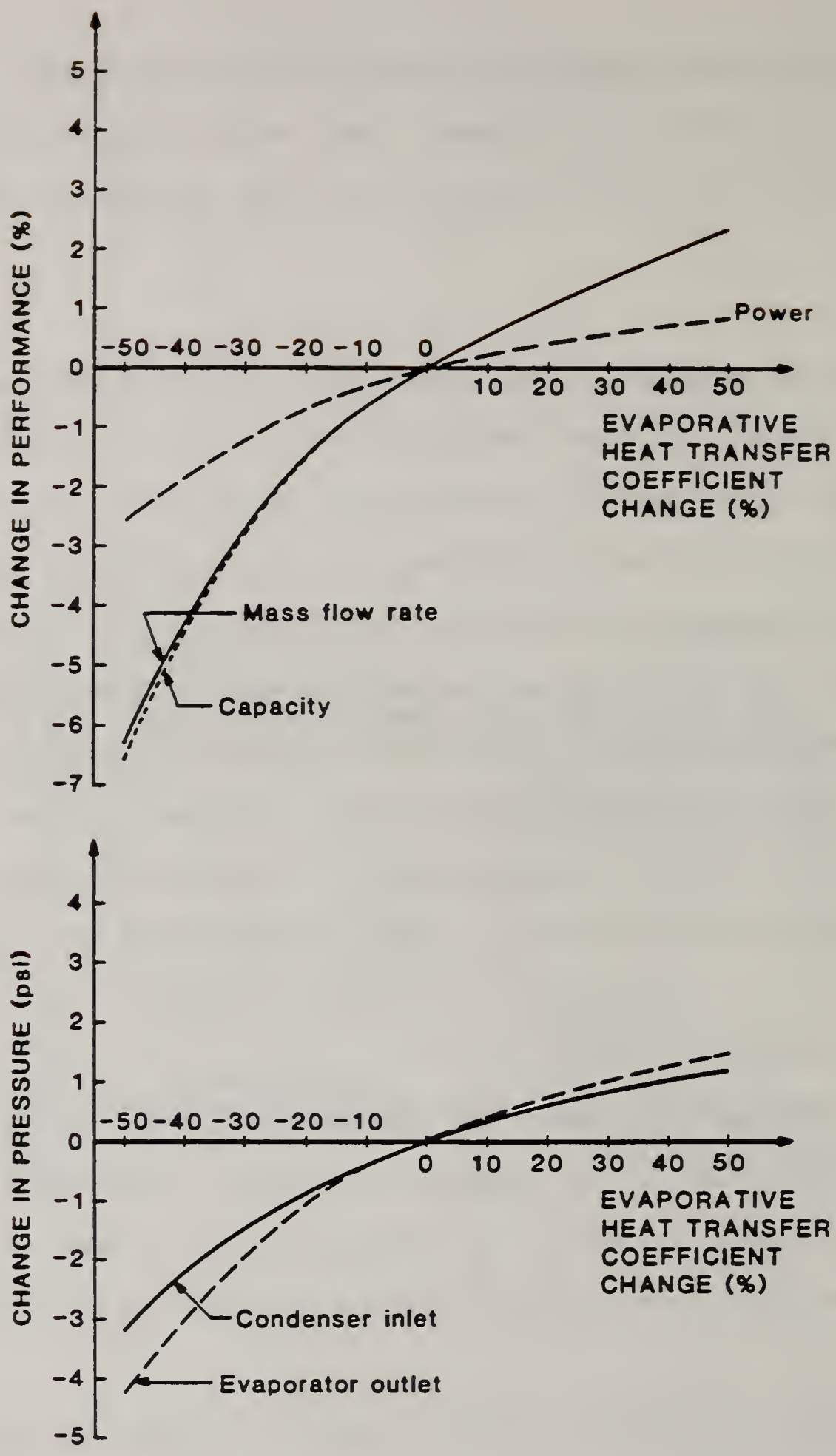

Figure 8. Sensitivity of performance of a heat pump on change in the evaporative heat transfer coefficient. 
increased refrigerant mass flow rate requires higher condenser temperature (pressure) in order to condense the refrigerant at this higher mass flow rate. Capacity of the system increases along with refrigerant mass flow rate (both curves coincide).

\subsection{Sensitivity to Change of Condensation Heat Transfer Coefficiert}

Uncertainties in determination of the condensation heat transfer coefficient are similar to those of the evaporation heat transfer coefficient. The condensation heat transfer coefficient may al so be enhanced by roughed inner surface or be degraded if a mirture is used. Therefore, just as with the evaporative coefficient, the selection of the appropriate value is application as well as property dependent.

Simalation results are show in Figure 9. A change of the condensation heat transfer coefficient makes greater impact when the coefficient is degraded than when it is improved. Decrease in the condensation heat transfer coefficient canses a rise in condenser pressure in order to condense flowing Iefrigerant. Increased condenser pressure is associated with only a weak evaporator pressure increase, thus the refrigerant mass flow rates remain al most nuchanged. Stronger changes (decreases) in capacity with decreased heat transfer coefficient is a result of a decreased enthalpy change in the evaporator resulting fram higher condenser pressure and higher liquid enthal py at the expansion device inlet with enthal py at the evaporator outlet almost unchanged. Compressor power change corresponds to changes in the condenser pressure which changed compressor compression ratio. 

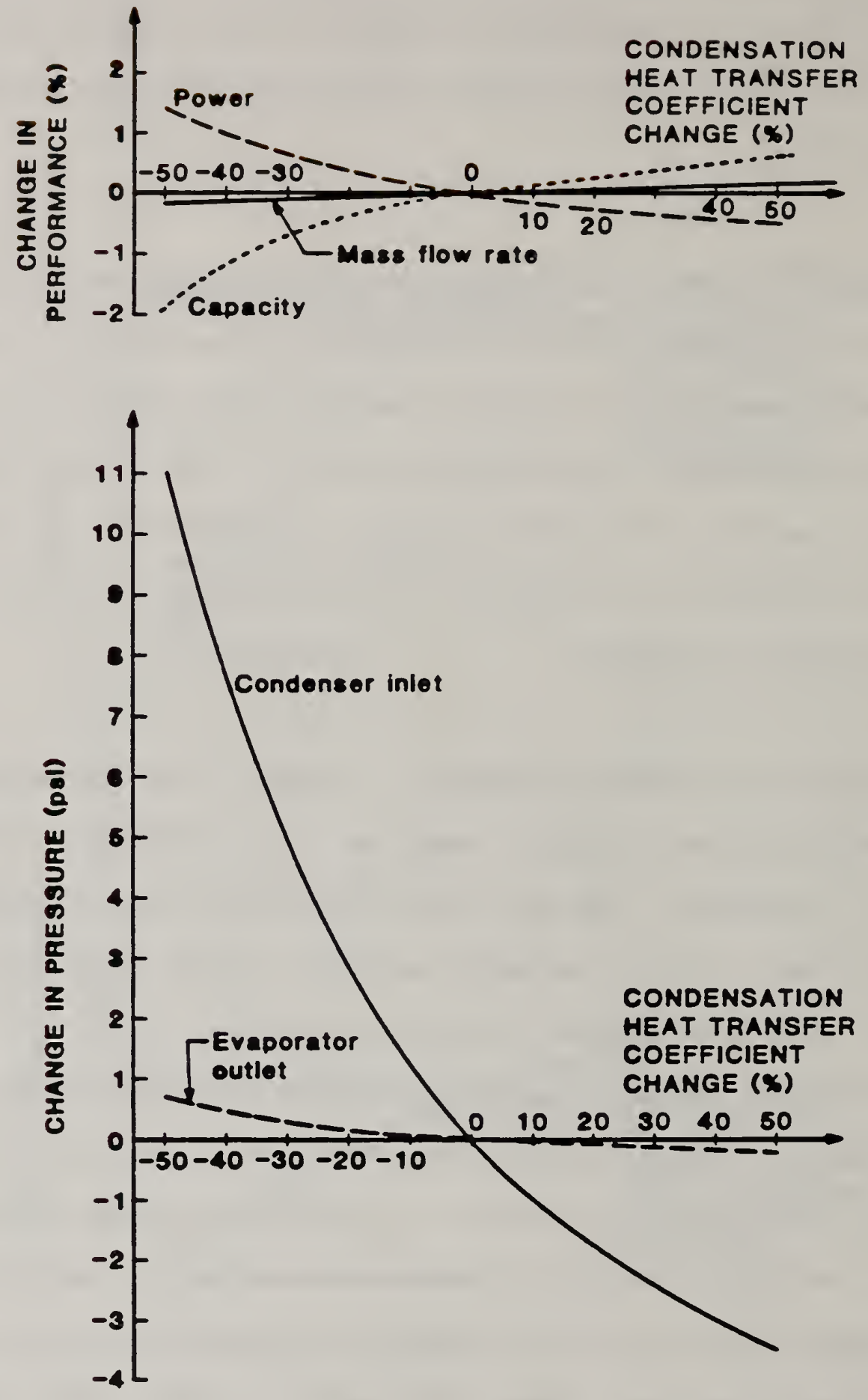

Figre 9. Sensitivity of performance of a heat pump on a change in the condensation heat transfer coefficient. 


\subsection{Sensitivity to Change of Evaporation Pressure Drop}

The evaporative pressure drop was altered in the range from $-50 \%$ to $+100 \%$, to cover possible uncertainty for pressure drop evaluation as well as cases of increased pressure drop in tubes with roughed inner surface for e nhanced beat transfer coefficient. Simolation results are quite 1 inear (Figure 10 ). Increased pressure drop decreases the compressor suction pressure and suction vapor density. Refrigerant mass flow rate decreases and pressure in the condenser al so decreases since a smaller temperature difference be tween the ambient air and the condenser is required to condense refrigerant flowing at the lower rate. Refrigerant mass flow rate decrease results in capacity decrease (both curves coincide).

\subsection{Sensitivity to Change of Condensation Pressure Drop}

Condensation pressure drop was al tered within the same range as evaporative pressure drop: $-50 \%,+100 \%$. Simulation results showed small sensitivity to altered two-phase pressure drop in the condenser. Capacity and power were changed within -0.1 and $+0.1 \%$ range.

\subsection{Sensitivity to Change of More than One Parameter}

Performance sensitivity to more than one parameter's variation can be evaluated by reading the figures for the individual parameters involved and multiplying the individual performance changes. For example, if a roughened inside tube surface enhanced the inside tube heat transfer coefficient by $40 \%$ at the expense of increased pressure drop of $40 \%$, the resultant change of system cafacity, if such tubes were employed in the evaporator, would be 

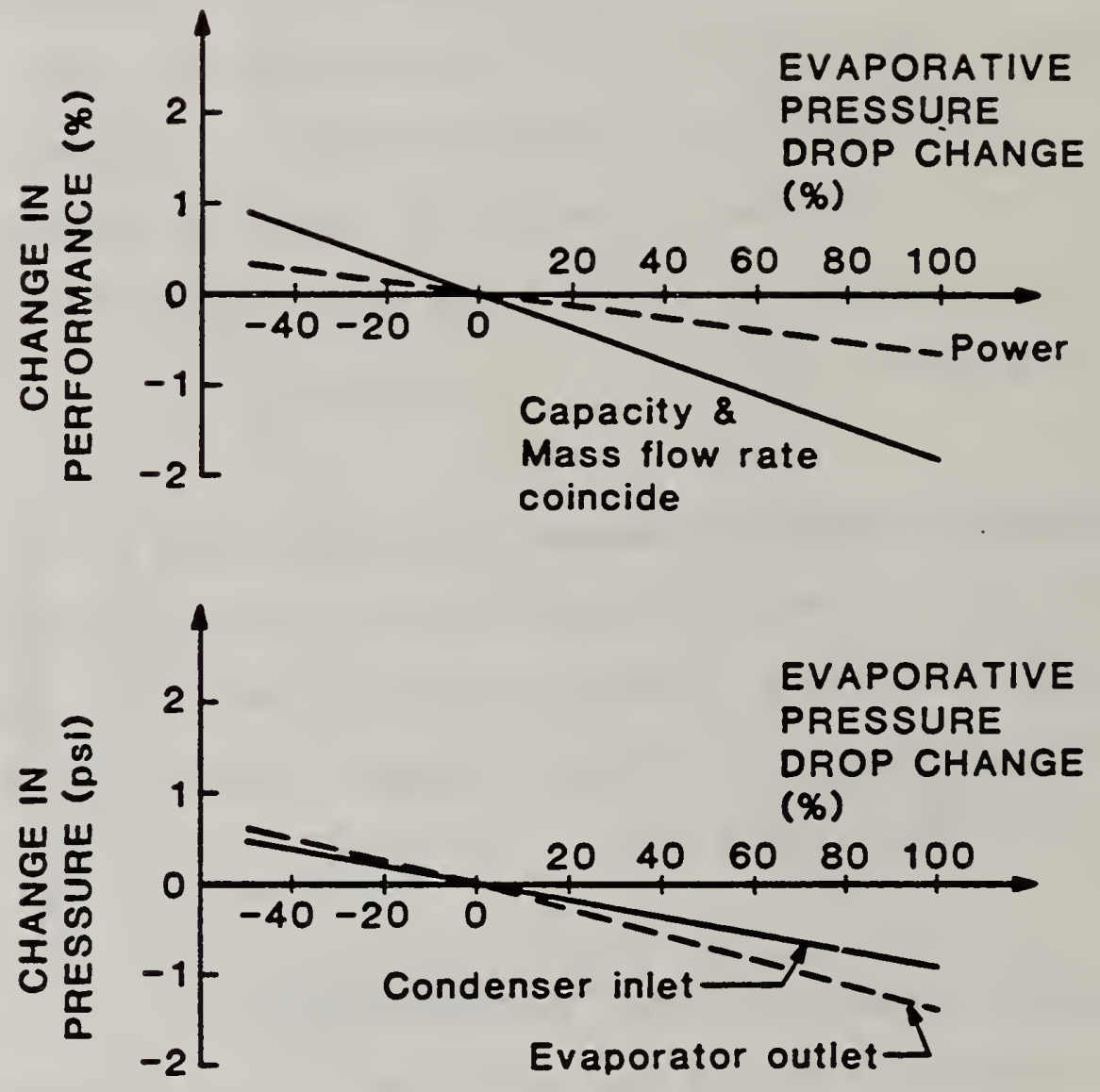

Figure 10. Sensitivity of performance of a heat pump on a change in the evaporative pressure drop. 
$1.020 \cdot 0.993=1.013$ where:

1.020 corresponds to $2 \%$ capacity increase doe to the increased inside tube heat transfer coefficient (read fram Figure 8),

0.993 corresponds to $0.7 \%$ capacity decrease due to increased evaporative pressure drop (read from Figure 10).

This superimposing of effects can be done since system sensitivity was evaluated based on comparable thermodynamic cycles optimized by the same criteria by imposing $10^{\circ} \mathrm{F}$ vapor superheat at the compressor can inlet and $10^{\circ} \mathrm{F}$ 1 iquid sabcooling at the expansion device inlet. This procedure was al so verified by results of simalation runs in wich more than one parameter was varied.

3.14 Combined Effect of Refrigerant Properties Uncertainties on Prediction of System PeIformance

Accuracy of performance prediction may suffer for two reasons: inadequate hardware modeling algorithms, and inaccurate fluid property prediction. The performance prediction uncertainty band due to inadequacy of hardware modeling algorithms is, by definition, specific for each particular computer model. This ancertainty band can be found by comparing simnlation and 1 aboratory test results for different model heat pumps. Differences of disagreement between predicted and tested performance for different heat pump models would indicate the uncertainty band due to the inadequacy of simulation model algorithms.

This study was performed to provide a methodology for evaluation of sensitivity of performance prediction on nocertainties of refrigerant properties. This methodology depends on combining effects of individual parameters on system performance. Though results were generated simulating a 
heat pump charged with refrigerant 22, the metbodology is applicable to any refrigerant since it was formelated on a relative basis. Sensitivity of performance prediction is difficult to determine rigorously because the errors with wich fluid properties values are used in the simulation process are anknown. In addition, errors in fluid property values may have a cancelling effect in affecting the performance prediction, or a superimposing effect causing the simalation results to be far of $f$.

The uncertainty band due to inaccurate refrigerant property $v a 1$ ues will be different for different refrigerants since not al I refrigerants have been equaliy investigated and their properties equaliy well known In order to provide an indication of the ancertainty in performance prediction which may result from ancertainty in fluid properties, a case for refrigerant 22 is presented be 1 or.

Previous sections and figures allow identification of the parameters wich have the most significant impact on perfomance predictions and should be considered. These parameters are: 1 iquid thermal conductivity, 1 iquid viscosity, vapor specific vol we, evaporation and condensation beat transfer coefficients, and evaporation pressure drop. It is assumed here that all property ancertainties taken into account have a superimposing effect on system capacity. Two scenarios are considered: one when the error in performance prediction is equal to the mean deviation for a given property correlation, and the second when the maximum deviation is taken into accout. For R-22 there are a few correlations that were checked against a broad data bank and mean and marimum deviations were evaluated. These correlations for the following parameters are: 
Mean Deviation (\%) MazDeviation (\%) Sonrce
1 iquid themal conductivity
2.1
8.5
1 iquid $v$ iscosity
2.5
5.9
evaporation heat transfer coefficient 25.0
58.0

For the condensation heat transfer coefficient mean and mazimum deviations were assumed to be the same as for the evaporation heat transfer coefficient. Deviations for vapor specific volme were assumed to have values of $0.5 \%$ (max) and $0.25 \%(\mathrm{~min})$.

Reading system performance change for each property from the fignies and combining the individual effects yielded an uncertainty of $3.7 \%$ for capacity, and $3.1 \%$ for COP prediction in the minimum deviation case, and respective uncertainties of $12.9 \%$ and $10.9 \%$ for the maximum deviation case. The most influential single parameter appeared to be the evaporative heat transfer coefficient which contributed approximately $60 \%$ to the calculated uncertainties for capacity and COP predictions.

As far as other refrigerants and their mirtures are concerned, it is expected that performance prediction uncertainty will be greater. An important conclusion that can be drawn for all refrigerants from the R22 example is that an error in the value of the evaporation heat transfer coefficient has a significant weight and evalution of this parameter alone may provide a rough indication of the performance prediction uncertainty for single component Iefrigerants. For refrigerant mixtores a significant impact on performance prediction may come from errors in values of 1 iquid transport properties and 1 iquid specific volume. Influence of the se properties may differ 
significantly from one mixture to another depending on the experimental data base and correlations used. 
4. CONQUSIONS

Results of this study provide information on the effect uncertainties of individual parameters have on system performance prediction. This information should be helpful in evaluation of uncertainties in performance prediction for innovative refrigerants and their mixtures for which complete property information is usually not available. The results indicate 1 iquid transport properties, evaporative heat transfer coefficient and vapor density as those properties whose uncertainties have the most significant impact.

The effect of an individual parameter variation within the tested uncertainty I limits was found to be as high as $7.5 \%$ for capacity (for 1 iquid thermal conductivity) and $6 \%$ for power (for vapor specific volume). In reality the uncertainty of system performance prediction may be much higher since the value of each parameter is known with some uncertainty and they all influence the predicted level of performance. An example analysis for refrigerant 22 showed uncertainty of capacity and COP predictions can be as high as 12.90 and $10.9 \%$ if involved refrigerant parameters are known with an error equal to the maximum deviations of the considered property correlations. Since properties of refrigerant 22 are among the best known, the uncertainty of capacity and COP predictions for other refrigerants may be expected to be greater.

Discrepancy between heat pump laboratory test results and computer model predictions stem from uncertainties in refrigerant property prediction and inadequate hardware modeling al gorithms. Inaccurate refrigerant properties values should have a similar impact on performance predictions obtained by any computer model. This impact can be evaluated using findings contained in this report. The impact of inadequate modeling algorithms is specific for each

29 
computer model and bas to be evaluated using the particular model individus $11 \mathrm{y}$.

Fesults of this sensitivity study are system dependent (e.g. somewhat different results woulc be obtained for a system with different Ielative sizes of heat exchangers), however, no change of the relative importance of the investigated parameters should be observed. 


\section{REFERENCES}

1. National Engineering Laboratory, East Kilbride, Scotland. Private communication with D. A. Didion, 1983.

2. Morrison, G., The Importance of Including the Liquid Phase in Equations of State for Nonazeotropic Refrigerant Mirtures, ASHRAE Transactions, Vol. 91, Pt. 1, 1985 .

3. Radermacher, R., Ross, H., and Didion, D., Experimental Determination of Forced Convection Evaporative Heat Transfer Coefficients for Nonazeotropic refrigerant mixture, ASME Winter Annual Meeting, Paper No. 83WA $/$ MT $-54,1983$.

4. Federal Register, Part III, Test Procedures for Central Air Conditioners, Including Heat Pumps, Vo1. 44, No. 249, p. 76708, December 27, 1979.

5. Domanski, P. and Didion, D. , Computer Modeling of the Vapor Compression Cycle with Constant Flow Area Expansion Device, National Burear of Standards, Building Science Series 155, Ta shington, D. C. , 1983.

6. Downing, R.C., Refrigerant Equations, ASHRAE Transactions, Vo1. 80, Part 2, 1974

7. Colburn, A.P., A Method of Correlating Forced Convection Heat Transfer Data and a Comparison with Fluid Friction, AIChE Transactions, Vo1. 29, p. 174,1930 .

8. Pierre, B., Stromningsmotstand $\nabla$ id Kikande Kol dmedier, Kylteknisk Tidskrift, No. 6, December 1957.

9. Traviss, D.P., Baron, A.B., and Rohsenow, W.M., Forced-Convection Condensation Inside Tubes, Technical Report No. 72591-74, Massachusetts Institute of Technology, Cambridge, Massachusetts, 1971.

10. American Society of Heating, Refrigerating, and Air Conditioning Engineers, Inc., ASHRAE Handbook, Fundamentals Volnme, Atlanta, Ga., 1985 .

11. Pierre, B., F1 ow resistance with Boil ing Refrigerants, ASHRAE Journal, Se pt ember, 1964.

12. Lockhart, R. W. and Martinel1i, R. C., Chemical Engineering Progress, Vol. 45 , p. 39, 1949.

13. Reid, C.R., Pransnitz, J.M., and Sherwood, T.K., The Properties of Ga ses and Liquids, McGram-Hill, Inc., 1977.

14. Morrison, G. and McLinden M., Application of a Hard Sphere Equation of State to Refrigerants and Refrigerants Mirtures, National Burean of Standards, Technical Note, Washington, D.C., 1986, to be publ ished. 
15. Japanese Association of Refrigeration. Thermophysical Properties of Refrigeration-R-22, Osaba, Japan, 1975.

16. Gungor, K.E. and Winterton, R.M.S., A General Correlation for Flow Boiling in Tubes and Annoli, Int. J. Heat and Mass Transfer, Vol. 29, No. 3, pp. 351-358, 1986. 
APPENDIX A. EVALUATION OF THE THERMODYNAMIC PROPERTIES OF VAPOR

Equations used for evaluation of the thermodynamic properties were presented by Downing [6]. These equations are given below with appropriate constants for Refrigerant 22.

\section{Saturated Vapor Pressure}

$$
\log _{10} P=A+\frac{B}{T}+C \log _{10} T+D T+E\left(\frac{F-T}{T}\right) \log _{10}(F-T)
$$

where :

$$
\begin{aligned}
& P=\text { pressure (psia) } \\
& T=\text { vapor temperature (R) } \\
& A=29.357545 \\
& B=-3845.1932 \\
& C=-7.8610312 \\
& D=2.1909390 E-3 \\
& E=0.44574670 \\
& F=686.1
\end{aligned}
$$




\section{Eqration of State}

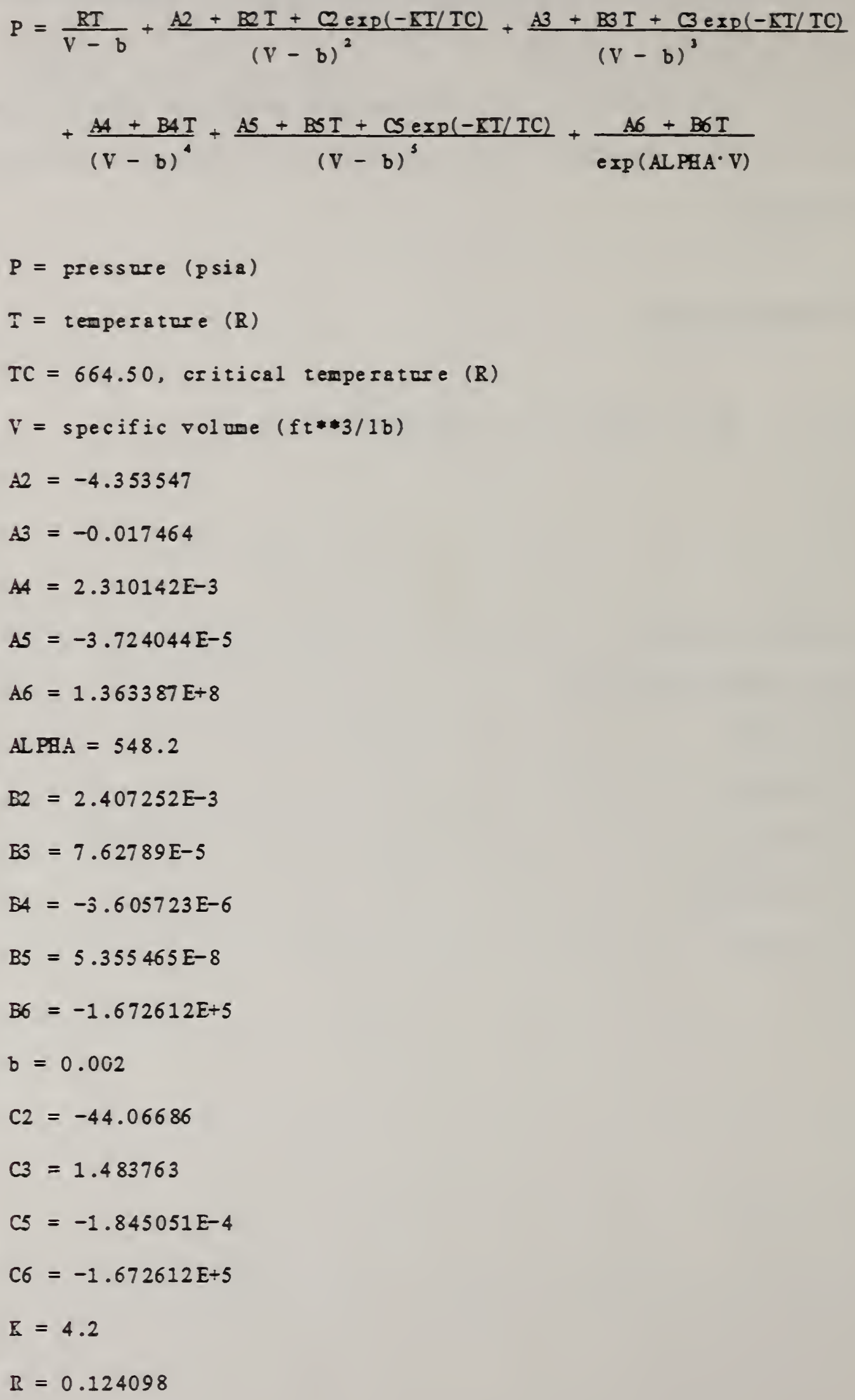




\section{Eeat Capacity of Vapor at Constant Volome}

$$
\begin{aligned}
C V= & a+b T+c T^{2}+\frac{f}{T^{2}}-\frac{J K^{2} T \exp (-K T / T C)}{T C^{2}}\left[\frac{C}{V-b}\right. \\
& \left.+\frac{C}{2(V-b)^{2}}+\frac{C S}{4(V-b)^{4}}\right]
\end{aligned}
$$

vbere :

$$
\begin{aligned}
& C_{V}=\text { heat capacity of vapor at constant volume (Bta/1b.F) } \\
& a=0.02812836 \\
& b=2.255408 E-4 \\
& c=-6.509607 \mathrm{E}-8 \\
& f=257.341 \\
& J=0.185053
\end{aligned}
$$

Other symbols as defined for the equation of state. 
Latent Heat of Vaporization

$$
\begin{aligned}
i_{f g}= & J T\left(V_{g}-V_{f}\right)\left[P(\ln 10)\left(\frac{-B}{T^{2}}+\frac{C}{T(1010)}\right)\right. \\
& \left.+D-E\left(\frac{\log _{10} e}{T}+\frac{F \log _{10}(F-T)}{T^{2}}\right)\right]
\end{aligned}
$$

(A4)

Where :

$$
\begin{aligned}
& i_{f g}=1 \text { stent beat of vaporization }(B t r / l b) \\
& J=0.185053 \\
& v_{g}=\text { specific volume of saturated vapor }(f t * * 3 / 1 b) \\
& v_{f}=\text { specific volume of saturated } 1 \text { quid }(f t * 3 / 1 b)
\end{aligned}
$$

Other symbols are as described for the vapor pressure equation.

36 


\section{Enthalpy of the Vapor}

$$
\begin{aligned}
i= & a T+\frac{b T^{2}}{2}+\frac{c T^{3}}{3}-\frac{f}{T}+J P V+J\left[\frac{A 2}{V-b}+\frac{A 3}{2(V-b)^{2}}\right. \\
& \left.+\frac{A 4}{3(V-b)^{3}}+\frac{A 5}{4(V-b)^{4}}+\frac{A 6}{A L P H A} / \exp (A L P H A \cdot V)\right] \\
& +J e \operatorname{sp}(-K T / T C)\left(1+\frac{K T}{T C}\right)\left[\frac{C}{V-b}+\frac{C 3}{2(V-b)^{2}}\right. \\
& \left.+\frac{C 5}{4(V-b)^{4}}\right]+62.4009
\end{aligned}
$$

where:

$i=$ enthalpy of vapor $(B t a / 1 b)$

symbol s A2, A3, A4, A5, A6, C2, C3, K, P, T, TC, V, ALPHA are as described for the equation of state symbols $J, a, b, c, f$ are as described for the heat capacity equation 


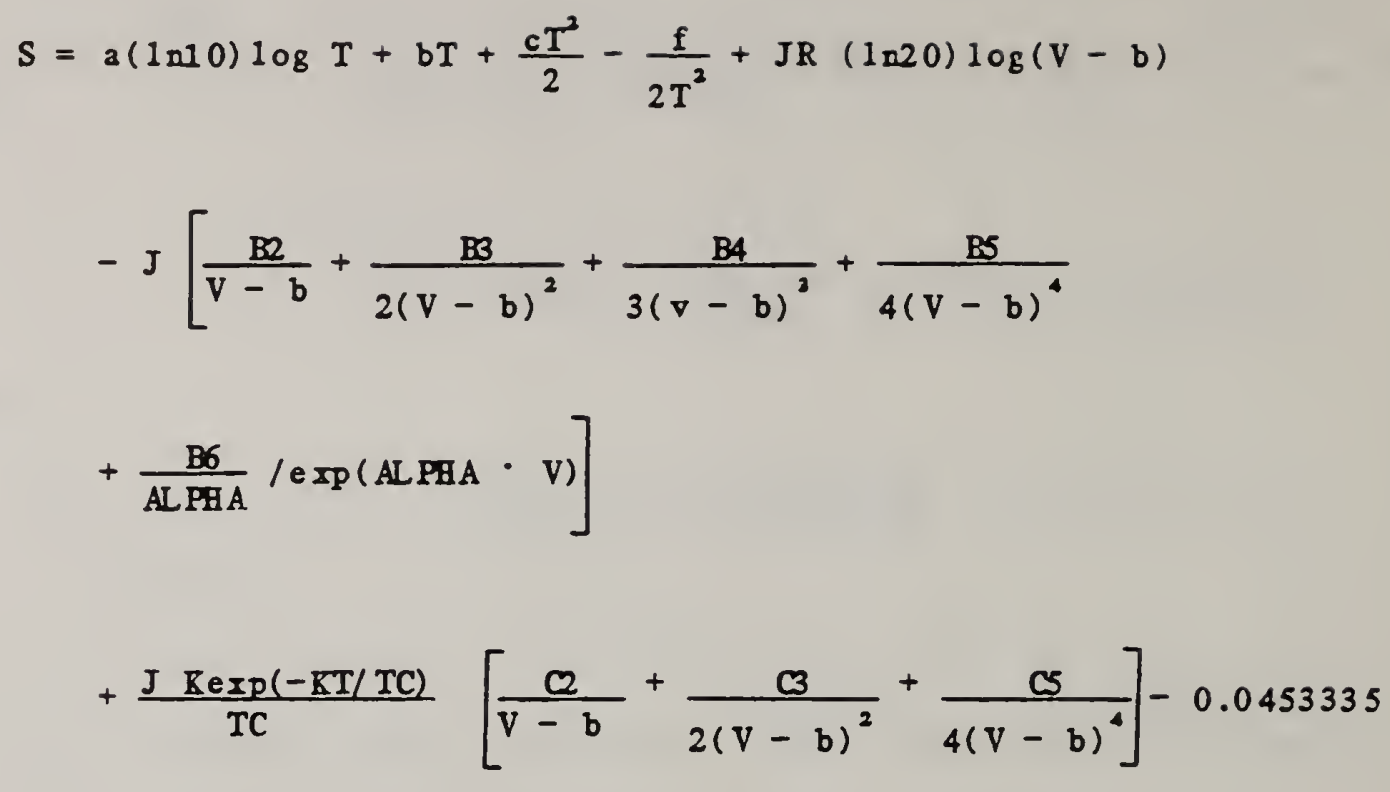

where $S$ = entropy of the vapor $(B t a /(1 b \cdot F))$

symbol s B2, B3, B4, B5, B6, C2, C3, C4, C5, K, T, TC, V,

ALPHA are as described for the equation of state.

symbols J, a, b, c, f are as described for the heat capacity equation. 
APPENDIX B. EVAL DATION OF THE INSIDE TUBE HEAT TRANSFER $O O E F F I C I E N T$ AND PRESSURE DROP OF REFRIGERANT

The following are inside tube heat transfer and pressure drop correlations used in the mode1, HPSIM. List of symbols is given at the end of this appendix.

Single-Phase Heat Transfer Coefficient

[7]

$$
\mathrm{h}=0.023 \frac{\mathrm{k}}{\mathrm{D}} \cdot \mathrm{Be}^{0.8} \cdot \mathrm{Pr}^{0.333}
$$

Evaporative Heat Transfer Coefficient

[8]

$$
h=0.0009 \frac{k_{L}}{D} \cdot \operatorname{Re}\left(J \cdot \Delta x \cdot i_{f g} / L\right) 0.5
$$

\section{Condensation Heat Transfer Coefficient}

$$
h=-\frac{k}{L}^{0.9} \cdot \operatorname{Re}_{L} \cdot P_{I} \cdot F_{1} \beta / F_{2}
$$

$$
\text { where: } \begin{aligned}
\beta & =1.00 \text { for } F 1 \leq 1 \\
\beta & =1.15 \text { for } F 1>1 \\
F 1 & =0.15\left(X_{t t}-1+2.85 \mathrm{X}_{t t} 0.524\right) \\
F 2 & =0.707 \cdot \operatorname{Pr}_{L} \cdot \operatorname{Re}_{L} 0.5 \text { for } \operatorname{Re}_{L}<50 \\
F 2 & =5 \cdot \operatorname{Pr}_{L}+5 \cdot \ln \left(1+\operatorname{Pr}_{L}\left(0.09636 \cdot \operatorname{Re}_{L} 0.585-1\right)\right) \text { for } 50<\operatorname{Re}<1125
\end{aligned}
$$




$$
\begin{aligned}
F 2= & 5 \cdot \mathrm{Pr}_{L}+5 \cdot \ln \left(1+\mathrm{Pr}_{L}\right)+2.5 \cdot \ln \left(0.00313 \cdot \mathrm{Re}_{\mathrm{L}} 0.812\right) \\
& \mathrm{for} \mathrm{Re}_{\mathrm{L}}<1125 \quad \text { (63) }
\end{aligned}
$$

Single-Phase Pressure Drop

$$
\begin{aligned}
& \Delta P=2 \cdot f \cdot G^{2} \cdot L /(D \cdot \rho) \\
& \text { where } f=0.046 \cdot \mathrm{Re}^{-0.2}
\end{aligned}
$$

Two-Phase Pressure Drop With Evaporation

$$
\begin{aligned}
& \Delta P=\left(f \cdot L / D+\Delta x / x_{m}\right) G^{2} \cdot V_{m} \\
& \text { where: } f=0.0185 \cdot \operatorname{Re}\left(L /\left(J \cdot i_{f_{g}} \cdot \Delta x\right)\right)^{0.25}
\end{aligned}
$$

$$
\begin{aligned}
& \Delta \mathrm{P}=\Delta \mathrm{P}_{\mathrm{L}} \cdot \Phi \\
& \text { where: } \Delta P_{L}=2 f((1-I) G)^{2} \cdot L /\left(D \cdot P_{L}\right) \\
& f_{L}=0.046 \cdot \operatorname{Re}_{L}-0.2 \\
& \Phi=10.0\left(A 0+A 1 \cdot B+A 2 \cdot B^{2}+A 3 \cdot B^{3}+A 4 \cdot B^{4}\right) \\
& \Phi=\text { correl ated based on [12] } \\
& \mathrm{AO}=1.4 \\
& A]=0.87917 \\
& A 2=0.14062
\end{aligned}
$$




$$
\begin{aligned}
& A 3=0.0010417 \\
& A 4=-0.00078125 \\
& B=\log _{10} X_{t t}
\end{aligned}
$$

\section{List of Symbols}

$C_{p}=$ specific heat at constant pressure

$D=$ inner tube diameter

$f=$ Fanning friction factor

$G=\frac{4 m}{\pi D}$, Iefrigerant mass flux

$h=$ forced convection heat transfer coefficient

$i_{f g}=1$ atent heat of evaporation/condensation

$J=$ mechanical equivalent of heat

$k=$ thermal conductivity

$L=$ trbe 1 ength

$m=$ refrigerant mass flow rate

$\mathbf{P}=$ pressure

PI $=\frac{\mu C P}{k}$, Prandt 1 number

$\operatorname{Re}=\frac{G D}{F}$, Reynolds nuber

$x=10 c a l$ quality, $x_{m}$ refers to mean quality

$V=$ specific $\nabla 01 \mathrm{mme}$

$V_{m}=V_{L}+x_{m}\left(V_{V}-V_{L}\right)$, two-phase mean specific vol me

$\Phi=$ Lockhart-Kartinelli correction factor for two phase pressure drop

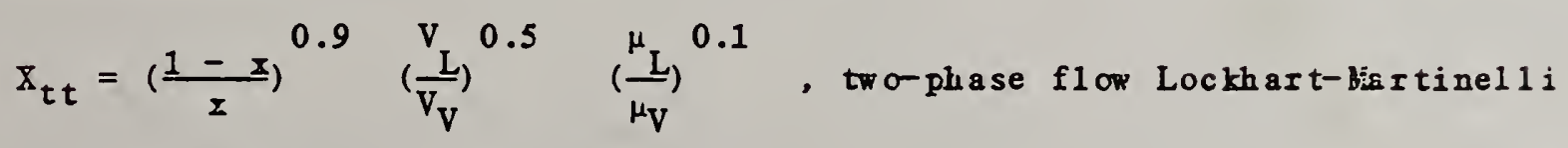
parameter for turbulent both 1 iquid and vapor 
$\rho=$ density
$\mu=$ absolute viscosity

Subscripts refer to:

$L=1$ iquid

$V=\nabla 8$ por

II = mean value 
NBS-114A IREV. 2-8C)

U.S. DEPT. OF COMM.

BIBLIOGRAPHIC DATA

SHEET (See in structions)

1. PUBLICATION OR REPORT NO. $86-3373$

4. TITLE AND SUBTITLE

Impact of Refrigerant Property Uncertainties on Prediction of Vapor Compression Cycle Performance

5. $A \cup T H O R(S)$

Piotr A. Domanski and David A. Didion

6. PERFORMING ORGANIZATION (If joint or other than NBS, see instructions)

7. Conerace/Grane No.

NATIONAL BUREAU OF STANDARDS

DEPARTMENT OF COMMERCE

WASHINGTON, D.C. 20234

9. SPONSORING ORGANIZATION NAME AND COMPLETE ADDRESS (Streer, City, Stote, ZIP)

Oak Ridge National Laboratory

Department of Energy

Oak Ridge, Tennessee 37830

10. SUPPLEMENTARY NOTES

Document describes a computer program; SF-185. FIPS Software Summary, is attached.

11. ABSTRACT (A 200-word or less foctual summary of most significant information. If document includes a significant bibliogrophy or literoture survey. mention it here)

This paper presents a sensitivity study of a vapor compression cycle in the form of a heat pump operating in the cooling mode. The study was performed with the aid of a detailed heat pump computer model; simulation runs were made for different parametric values and the capacity and power input were compared with results of a run using an unchanged value of the parameters. The effects on evaporator and condenser pressures, and refrigerant mass flow rate are given. The independent variables (parameters) include thermodynamic and transport properties, as well as the refrigerant flow heat transfer and pressure drop coefficients. When considering the state-of-the-art limits of the individual parameter uncertainties, those which had the most effect on system performance were liquid transport properties, evaporative heat transfer coefficient and vapor density.

12. KEY WORDS (Six to twelve entries; alphabetical order; capitalize only proper names; and separate key words by semicolons) air conditioner, heat pump, sensitivity study, thermodynamic properties, transport properties, vapor compression cycle

13. AVAILABILITY

X. Unlimited

For Official Distribution. Do Not Release zo NTIS

Order From Suderintendent of Documents, U.S. Government Printing Office, Washington, D.C. 20402.

- - Order From National Technical Information Service (NTIS). Springfield, VA. 22161
14. NO. OF PRINTED PAGES

51

15. Price

$\$ 13.95$ 


